\title{
Theoretical Studies on the Structural, Electronic and Optical Properties of the New $\pi$-conjugated Copolymers Based on Carbazole and Thiophene
}

\author{
Z. El Malki ${ }^{\mathrm{a}, \mathrm{b}}$, M. Bouachrine ${ }^{\mathrm{b}, \mathrm{c}^{*}}$, M. Hamidi ${ }^{\mathrm{b}, \mathrm{d}^{*}}$, L. Bejjit ${ }^{\mathrm{a}}$, and M. Haddad ${ }^{\mathrm{a}}$ \\ ${ }^{a}$ LASMAR (URAC 11), Faculté des Sciences, Université Moulay Ismail Meknès, Maroc \\ ${ }^{b}$ URMM/UCTA, FST Errachidia, Université Moulay Ismaïl, Meknès, Maroc \\ ${ }^{\mathrm{C}}$ UMIM, Faculté Polydisciplinaire de Taza, Université Sidi Mohamed Ben Abdellah, Taza, Maroc \\ ${ }^{\mathrm{d}}$ Faculté Polydisciplinaire d’Errachidia, Université Moulay Ismaïl, Meknès, Maroc
}

Received 14 April 2011, accepted in final revised form20 December 2011

\begin{abstract}
This work reports a theoretical investigation of $\pi$-conjugated oligomers constituted by $n$ units $(n=1-4)$ based on carbazole and ethylenedioxythiophene. The molecular geometry, torsional potential, electronic and optical properties of the oligomers [Cbz-(Edot) $\mathrm{n}_{\mathrm{n}} \mathrm{Cbz}$ ] ( $n=1-4)$ are investigated using DFT (B3LYP/3-21G*) calculations. The discussion is focused on the influence of chain length on the properties of these copolymers. The analyses of torsional angles for [Cbz-(Edot) ${ }_{4}-\mathrm{Cbz}$ ] reveal that the structure has a anti-planar conformation. The electronic properties of the molecules, HOMO, LUMO and $\mathrm{E}_{\mathrm{g}}$ (HOMOLUMO), are studied using B3LYP functional. The results have been compared with those of thiophene and ethylenedioxythiophene. The lowest excitation energies $\left(\mathrm{E}_{\mathrm{ex}}\right)$ and the maximal absorption wavelength $\left(\lambda_{\text {abs }}\right)$ are studied using the TD/DFT, ZINDO and CIS methods. The electronic transitions of the absorption spectrum derived by TD/DFT method give useful structural and electronic information for designing novel conducting organic polymer materials. The bridging effect by $\mathrm{C}=\mathrm{C}(\mathrm{CN})_{2}$ on the optoelectronic properties of the (carbazole-thiophene-carbazole) comonomer is investigated.
\end{abstract}

Keywords: Conducting polymer; Carbazole-(Ethylenedioxythiophene) ${ }_{n}$-Carbazole comonomers; DFT Optoelectronic properties; absorption coefficient; Bridging effect.

(C) 2012 JSR Publications. ISSN: 2070-0237 (Print); 2070-0245 (Online). All rights reserved.

doi:10.3329/jsr.v4i1.7450 J. Sci. Res. 4 (1), 119-133 (2012)

\section{Introduction}

Electrically conducting polymers have been considered for numerous applications including charge dissipation coatings [1], organic thin-film transistors [2], and conducting textiles [3].

In the last year, the poly(3,6-carbazole) and derivatives have been synthesized [4, 5]. Luminescent materials spanning the entire visible range have been prepared from these polymers [6], and can be used in organic light electronic devices (OLED) [7]. The

\footnotetext{
*Corresponding author: lrmm_fste@yahoo.fr
} 
polyvinylcarbazole (PVK) have significant specific properties (photoconductivity, photoluminescence and hole transport properties) [8, 9]. One of the most important factors of controlling physical properties is the bandgap, which is a current topic of research. The polymers with a low bandgap are desired in optoelectronic applications. Leclerc et al. [4, 5] have reported the spectroscopic and photophysical properties of carbazole-based molecules in solution. The absorption and emission energies of these copolymerized derivatives were correlated with their electronic transitions, as computed by ZINDO calculations performed on optimized HF/6-31G(d) geometries, and first relaxed excited state as obtained by RCIS/6-31G(d) calculations [10, 11]. The results demonstrated a good agreement between computed electronic transitions and the optical data. The geometric structures and electronic properties of the carbazole-based oligomers, were recently studied by Yang et al. [12, 13] and Surmtir et al. [14].

On the other hand, the poly(3,4-ethylenendioxythiophene) (PEDOT) showed a remarkable high stability, high electrical conductivity and a low optical band gap $[15,16]$ of approximately $1.6 \mathrm{eV}$, making this material to be a candidate for many industrial applications. As antistatic material, PEDOT is already being used industrially in a large scale. In this polymer the oxygen atoms of the dioxane ring are directly attached at the 3and 4-positions. PEDOT homopolymer is widely used as a conducting and hole-injecting electrode in organic light emitting diodes (OLEDs) [17]. Several EDOT based donoracceptor conjugated polymers with small band gaps have been reported [18-20]. Dkhissi et al. [21] have investigated the relative stability of the aromatic and quinoid-like structures for neutral PEDOT using ab initio SCF and DFT (density functional theory) calculations at the HF and B3LYP levels, respectively. Materials that combine properties of these two monomers (Cbz and EDOT) are attractive materials for a variety of applications in the electronic devices. Recently, the copolymer based carbazole and etyhlenedioxythiophene was synthesized by Sarac et al. [22]. In the present study, we report a theoretical study of the structural, electronic, and optical properties of (carbazole(3,4-etyhlemedioxythiophene) $)_{n}$-carbazole) [Cbz-(Edot $)_{n}$-Cbz]. The model compound of the molecular structure is shown in Fig. 1. We will examine the insertion effect of bridging by $\mathrm{C}=\mathrm{C}(\mathrm{CN})_{2}$ groups on the energy gaps and the electronic properties of the (Carbazole-Bithiophene-Carbazole) (Cbz-BThi-Cbz) and (Carbazole-QuaterthiopheneCarbazole) (Cbz-QThi-Cbz) comonomers. These properties will be compared with those of the studied comonomers. Bridging is one of several chemical modifications which have been intensively used by several groups that aim at decreasing the band gaps of the systems [23, 24].

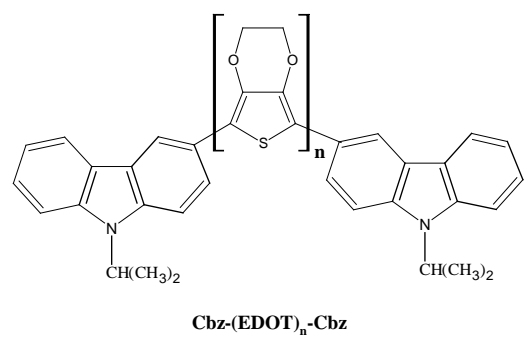

Fig. 1. Chemical structure of the oligomers [Cbz-(Edot $)_{\mathrm{n}}$-Cbz]. 


\section{Computational Methods}

The molecular geometries of the several oligomers [Cbz-(Edot) $)_{\mathrm{n}}-\mathrm{Cbz}$ ] $(n=1-4)$, were fully optimized using the DFT method of three-parameter compound of Becke (B3LYP) [25]. All calculations in this work were carried out using Gaussian 03 program package [26]. The 3-21G* basis set was used for all calculations [27-30]. The conformational analysis of all oligomers was done by changing the torsional angles between adjacent carbazole and ethylenedioxythiophene rings by $20^{\circ}$ steps in the same direction in order to obtain the final torsional angles of the conformers in each minimum. The HOMO, LUMO and gap (HOMO-LUMO) energies were also deduced for the stable structures. We employed the linear extrapolation technique in this research, which has been successfully employed to investigate several series of polymers [31-34]. Electronic transition energies and oscillator strengths of oligomers were obtained by using various methods (semiempirical ZINDO [35], configuration interaction singles (CIS) [36] and time dependent density functional theory (TD/DFT) [37].

\section{Results and Discussion}

\subsection{Conformation and structural properties}

\subsubsection{Conformational analysis}

The results of the torsion potential of the several oligomers obtained with B3LYP/3-21G* level, are presented in Fig. 2. All the curves obtained for the oligomers have the same behavior and they present four extrema, two maxima situated at 0 and $90^{\circ}$ and two minima located at about 20 and $180^{\circ}$. The potential energy curves show the existence, for

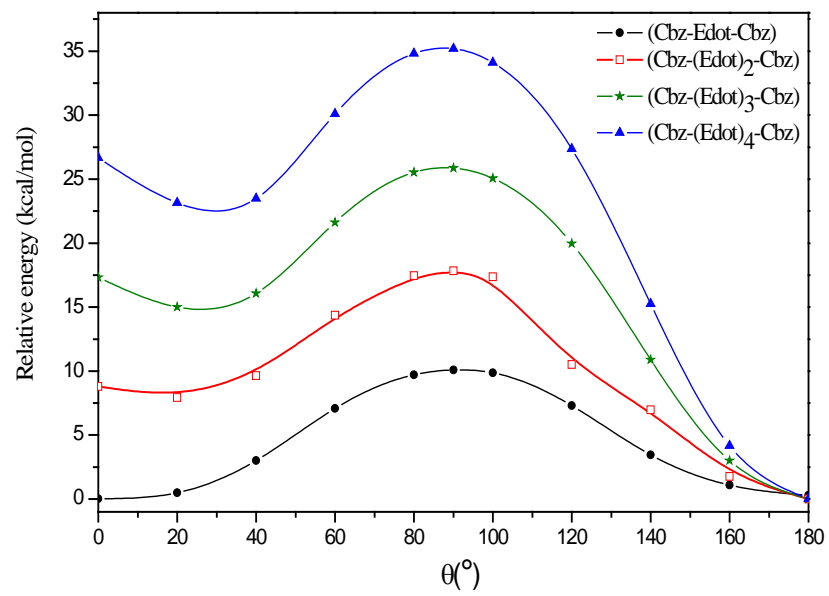

Fig. 2. Potential energy curves of [Cbz-(Edot) $\left.)_{n}-\mathrm{Cbz}\right](n=1-4)$ obtained by B3LYP/3-21G* level. 
all oligomers, of two stable conformations: a syn-conformation and anti-conformation with the anti-one being the most stable (Table 1). The anti-conformation becomes nearly anti-planar for (Cbz-(Edot) ${ }_{3}$-Cbz] and (Cbz-(Edot) ${ }_{4}$-Cbz] oligomers. The syn-planar and perpendicular conformations energy barriers increase with the chain length while antiplanar energy barriers remain identical for all the oligomers (Table 2). The steric effect felt for anti-planar conformation remains unaltered with the increase of the number of rings. Similarly, HF/6-31G(d) optimizations of $n$-EDOT oligomers [38, 39] and B3LYP/6-31G(d) optimization of $n$-THP oligomers [40-42] provided an anticonformation in all cases.

Table 1. Angle of torsion cisoide and transoide $\left(^{\circ}\right)$ conformation of copolymers [Cbz-(Edot) $)_{\mathrm{n}}$-Cbz] $(n=1-4)$, obtained by B3LYP/3-21G* level.

\begin{tabular}{lcccc}
\hline $\begin{array}{l}\text { No of } \\
\text { rings }\end{array}$ & $n=1$ & $n=2$ & $n=3$ & $n=4$ \\
\hline$\theta_{1}($ syn $)$ & 4.81 & 2.00 & 3.37 & 1.90 \\
$\theta_{1}$ (anti) & 177.51 & 175.37 & 177.40 & 178.29 \\
$\theta_{2}$ (syn) & 3.08 & 37.56 & 38.11 & 37.96 \\
$\theta_{2}$ (anti) & 177.71 & 179.88 & 179.84 & 179.81 \\
$\theta_{3}$ (syn) & - & 4.69 & 37.67 & 38.10 \\
$\theta_{3}($ anti) & - & 179.94 & 179.89 & 179.73 \\
$\theta_{4}($ syn $)$ & - & - & 5.38 & 38.34 \\
$\theta_{4}($ anti) & - & - & 179.70 & 179.27 \\
$\theta_{5}$ (syn) & - & - & & 5.92 \\
$\theta_{5}($ anti) & - & - & & 174.33 \\
\hline
\end{tabular}

Table 2. Relative energy (eV) of all conformations of all oligomers [Cbz-(Edot) $)_{\mathrm{n}}$-Cbz] ( $n=1-4)$, calculated by B3LYP/3-21G* level.

\begin{tabular}{lccccc}
\hline Oligomer & $\begin{array}{c}\text { Plane } \\
\left(0^{\circ}\right)\end{array}$ & $\begin{array}{c}\text { Syn- } \\
\text { plane }\end{array}$ & $\begin{array}{c}\text { Perpendicular } \\
\left(90^{\circ}\right)\end{array}$ & $\begin{array}{c}\text { Anti- } \\
\text { gauche }\end{array}$ & $\begin{array}{c}\text { Anti-plane } \\
\left(180^{\circ}\right)\end{array}$ \\
\hline [Cbz-Edot-bz] & 0.001 & 0.00 & 0.437 & 0.012 & 0.013 \\
{$[\text { Cbz-(Edot })_{2}$-Cbz] } & 0.381 & 0.286 & 0.773 & 0.00 & 0.0005 \\
{$\left[\right.$ Cbz-(Edot) ${ }_{3}$-Cbz] } & 0.750 & 0.565 & 1.121 & 0.00 & 0.0003 \\
{$[\text { Cbz-(Edot })_{4}$-Cbz] } & 1.156 & 0.877 & 1.526 & 0.00 & 0.001 \\
\hline
\end{tabular}

\subsubsection{Geometric properties}

We present in Table 3, the optimized structural parameters (corresponding to the global minimum optimized structure) for all oligomers (Cbz-(Edot) $\left.)_{n}-C b z\right](n=1-4)$ as calculated 
by B3LYP/3-21G* level. The optimized geometric model for [Cbz-(Edot) ${ }_{4}$-Cbz] with B3LYP/3-21G* method is shown in Fig. 3. There are no significant differences among the bond lengths obtained for all oligomers in their ground state. Concerning the rotational angle, the results obtained for [Cbz-Edot-Cbz] show that the stable conformation is synplanar, on the other hand, from $n=2$ and up, the structures exhibits the anti-planar conformation. The results with the change in rotational angle are similar to that obtained for oligothiophenes [43] and PRODOT (poly(3,4-propylenedixoythiophene)) [44] ( $\theta_{\mathrm{i}} \approx$ $178^{\circ}$ ), which all adopt anti-planar conformation.

Table 3. Optimized structural parameters, bond length (in $\AA$ ) and inter-ring twisting angle ( ${ }^{\circ}$ ) of oligomers [Cbz-(Edot) $)_{n}$-Cbz] $(n=1-4)$ obtained by B3LYP/3-21G* level.

\begin{tabular}{|c|c|c|c|c|}
\hline No. of rings & 1 & 2 & 3 & 4 \\
\hline $\mathrm{C}_{1} \mathrm{C}_{2}$ & 1.393 & 1.393 & 1.393 & 1.393 \\
\hline $\mathrm{C}_{2} \mathrm{C}_{3}$ & 1.396 & 1.396 & 1.397 & 1.396 \\
\hline $\mathrm{C}_{3} \mathrm{C}_{4}$ & 1.452 & 1.451 & 1.451 & 1.451 \\
\hline $\mathrm{C}_{4} \mathrm{C}_{5}$ & 1.391 & 1.391 & 1.391 & 1.391 \\
\hline $\mathrm{C}_{5} \mathrm{C}_{6}$ & 1.407 & 1.405 & 1.405 & 1.405 \\
\hline $\mathrm{C}_{6} \mathrm{C}_{7}$ & 1.461 & 1.460 & 1.460 & 1.460 \\
\hline $\mathrm{C}_{7} \mathrm{C}_{8}$ & 1.377 & 1.380 & 1.380 & 1.380 \\
\hline $\mathrm{C}_{8} \mathrm{C}_{9}$ & 1.431 & 1.423 & 1.422 & 1.422 \\
\hline $\mathrm{C}_{9} \mathrm{C}_{10}$ & 1.377 & 1.375 & 1.375 & 1.375 \\
\hline $\mathrm{C}_{10} \mathrm{C}_{11}$ & 1.461 & 1.427 & 1.427 & 1.427 \\
\hline $\mathrm{C}_{11} \mathrm{C}_{12}$ & 1.408 & 1.369 & 1.372 & 1.372 \\
\hline $\mathrm{C}_{12} \mathrm{C}_{13}$ & 1.392 & 1.421 & 1.413 & 1.413 \\
\hline $\mathrm{C}_{13} \mathrm{C}_{14}$ & 1.452 & 1.373 & 1.371 & 1.372 \\
\hline $\mathrm{C}_{14} \mathrm{C}_{15}$ & 1.396 & 1.461 & 1.428 & 1.428 \\
\hline $\mathrm{C}_{15} \mathrm{C}_{16}$ & 1.392 & 1.405 & 1.369 & 1.372 \\
\hline $\mathrm{C}_{16} \mathrm{C}_{17}$ & - & 1.391 & 1.422 & 1.413 \\
\hline $\mathrm{C}_{17} \mathrm{C}_{18}$ & - & 1.451 & 1.373 & 1.372 \\
\hline $\mathrm{C}_{18} \mathrm{C}_{19}$ & - & 1.396 & 1.461 & 1.427 \\
\hline $\mathrm{C}_{19} \mathrm{C}_{20}$ & - & 1.392 & 1.405 & 1.376 \\
\hline $\mathrm{C}_{20} \mathrm{C}_{21}$ & - & - & 1.391 & 1.421 \\
\hline $\mathrm{C}_{21} \mathrm{C}_{22}$ & - & - & 1.451 & 1.380 \\
\hline $\mathrm{C}_{22} \mathrm{C}_{23}$ & - & - & 1.396 & 1.460 \\
\hline $\mathrm{C}_{23} \mathrm{C}_{24}$ & - & - & 1.392 & 1.407 \\
\hline $\mathrm{C}_{24} \mathrm{C}_{25}$ & - & - & - & 1.391 \\
\hline $\mathrm{C}_{25} \mathrm{C}_{26}$ & - & - & - & 1.451 \\
\hline $\mathrm{C}_{26} \mathrm{C}_{27}$ & - & - & - & 1.396 \\
\hline $\mathrm{C}_{27} \mathrm{C}_{28}$ & - & - & - & 1.393 \\
\hline
\end{tabular}


Table 3 (contd.)

\begin{tabular}{ccccc}
\hline$\theta_{1}$ & 4.81 & 175.37 & 177.40 & 178.29 \\
$\theta_{2}$ & 3.08 & 179.88 & 179.84 & 179.81 \\
$\theta_{3}$ & - & 179.94 & 179.89 & 179.73 \\
$\theta_{4}$ & - & - & 179.70 & 179.27 \\
$\theta_{5}$ & - & - & - & 174.33 \\
\hline
\end{tabular}

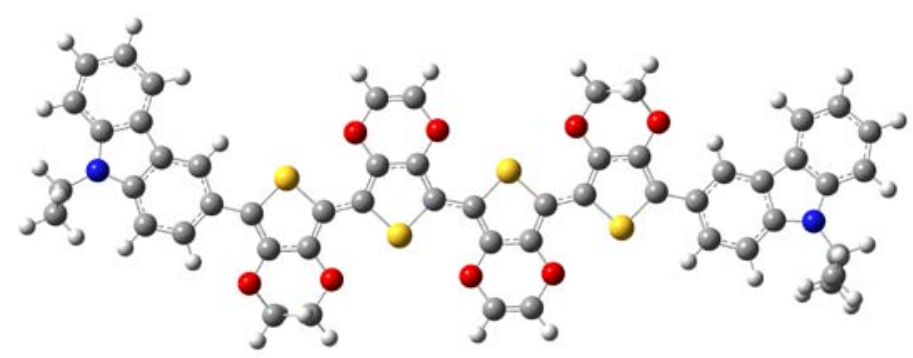

Fig. 3. Optimized structure of [Cbz-(Edot) ${ }_{4}$-Cbz] obtained by B3LYP/3-21G* level.

\subsection{HOMO, LUMO and band gaps}

There are two theoretical approaches for calculating the energy gap. One way is based on the ground-state properties, from which the band gap is estimated from the energy difference between the highest occupied molecular orbital (HOMO) and the lowest unoccupied molecular orbital (LUMO) [45, 46], when $n=\infty$, termed the HOMO-LUMO gaps $\left(\Delta_{\mathrm{H}-\mathrm{L}}\right)$. The TD/DFT, which has been used to study systems of increasing complexity due to its relatively low computational cost and also to include in its formalism the electron correlation effects, is also employed to extrapolate energy gap of polymers from the calculated first dipole-allowed excitation energy of their oligomers. The HOMO, LUMO, $\Delta E_{\mathrm{n}}$ (between HOMO and LUMO) are computed and the results are given in Table 4. The obtained results for $(\mathrm{EDOT})_{\mathrm{n}}$ and $(\mathrm{THP})_{\mathrm{n}}$ [39], are presented also for comparison. When we compare the various values of calculated gap of the longest oligomer, we note that the energy gaps in [Cbz-(Edot) $)_{\infty}-\mathrm{Cbz}$ ] $(1.83 \mathrm{eV})$ are dramatically lower than those in $(E D O T)_{\infty}(2.17 \mathrm{eV})$ and $(\mathrm{THP})_{\infty}(2.34 \mathrm{eV})$, which indicates that, the additive conjugated monomers, facilitate the decreasing of the energy gaps. As is usual in $\pi$-conjugated systems, with the increasing conjugation lengths the HOMO energies increase, whereas the LUMO energies decrease in all series. The HOMO-LUMO gaps $\left(\Delta_{\mathrm{H}-\mathrm{L}}\right)$ and lowest singlet excited energies $\left(\mathrm{E}_{\mathrm{ex}}\right)$ are both listed in Table 5 together with the results obtained for $(\mathrm{Cbz})_{\mathrm{n}}$ [13]. Comparing the calculated values, we can find the 
superiority of carbazole-based ethylenedioxythiophene and the influence of the introduction of charge carriers.

Table 4. The HOMO, LUMO, $\Delta E_{\mathrm{n}}$ (HOMO-LUMO), values of energy (in eV) of [Cbz-(Edot) $\left.)_{\mathrm{n}-2}-\mathrm{Cbz}\right],(\mathrm{EDOT})_{\mathrm{n}}$ [39] and (THP) $)_{\mathrm{n}}$ [39] $(n=3-8)$.

\begin{tabular}{|c|c|c|c|c|c|c|c|c|c|}
\hline \multirow[t]{2}{*}{$\begin{array}{l}\text { No. of } \\
\text { rings }\end{array}$} & \multicolumn{3}{|c|}{ [Cbz-(Edot) $\left.)_{\mathrm{n}-2}-\mathrm{Cbz}\right]$} & \multicolumn{3}{|c|}{$(\text { EDOT })_{n}[39]$} & \multicolumn{3}{|c|}{$(\mathrm{THP})_{\mathrm{n}}$ [39] } \\
\hline & HOMO & LUMO & $\Delta E_{\mathrm{n}}$ & HOMO & LUMO & $\Delta E_{\mathrm{n}}$ & HOMO & LUMO & $\Delta E_{\mathrm{n}}$ \\
\hline 3 & -4.532 & -0.925 & 3.607 & -4.54 & -0.87 & 3.67 & -5.31 & -1.49 & 3.82 \\
\hline 4 & -4.477 & -1.301 & 3.176 & -4.32 & -1.02 & 3.30 & -5.15 & -1.71 & 3.44 \\
\hline 5 & -4.435 & -1.490 & 2.945 & -4.18 & -1.11 & 3.07 & -5.07 & -1.84 & 3.23 \\
\hline 6 & -4.287 & -1.526 & 2.761 & -4.09 & -1.16 & 2.92 & -5.01 & -1.93 & 3.08 \\
\hline 7 & -4.147 & -1.561 & 2.586 & -4.02 & -1.20 & 2.82 & -4.98 & -2.00 & 2.98 \\
\hline 8 & -4.144 & -1.651 & 2.493 & -3.99 & -1.23 & 2.76 & -4.95 & -2.04 & 2.91 \\
\hline$\infty$ & - & - & 1.83 & - & - & 2.17 & - & - & 2.34 \\
\hline
\end{tabular}

Table 5. The HOMO-LUMO gaps $\left(\Delta_{\mathrm{H}-\mathrm{L}}\right)(\mathrm{eV})$ obtained by B3LYP/3-21G* level and the lowest excitation energies $\left(E_{\mathrm{ex}}\right)(\mathrm{eV})$ obtained by TD/DFT of [Cbz-(Edot $\left.)_{\mathrm{n}-2}-\mathrm{Cbz}\right]$ and $(\mathrm{Cbz})_{\mathrm{n}}[13](n=3-8)$.

\begin{tabular}{ccc}
\hline Oligomer & $\Delta_{\mathrm{H}-\mathrm{L}}$ & $E_{\text {ex }}(\mathrm{TD})$ \\
\hline$(\mathrm{Cbz})_{\mathrm{n}}[13]$ & & \\
$\mathrm{n}=3$ & 3.90 & 3.58 \\
$\mathrm{n}=4$ & 3.75 & 3.42 \\
$\mathrm{n}=5$ & 3.67 & 3.34 \\
$\mathrm{n}=6$ & 3.63 & 3.31 \\
$\mathrm{n}=7$ & 3.61 & 3.27 \\
$\mathrm{n}=\infty$ & 3.42 & $\mathbf{3 . 0 8}$ \\
Cbz-(Edot $)_{\mathrm{n}-2^{2}-\mathrm{Cbz}}$ & & \\
$\mathrm{n}=3$ & 3.61 & 3.29 \\
$\mathrm{n}=4$ & 3.17 & 2.88 \\
$\mathrm{n}=5$ & 2.94 & 2.65 \\
$\mathrm{n}=6$ & 2.76 & 2.46 \\
$\mathrm{n}=7$ & 2.58 & 2.30 \\
$\mathrm{n}=8$ & 2.49 & 2.21 \\
$\mathrm{n}=\infty$ & $\mathbf{1 . 8 3}$ & $\mathbf{1 . 5 7}$ \\
\hline
\end{tabular}




\subsection{Absorption spectra}

We present in Table 6 the calculated absorption $\left(\lambda_{\max }\right)(\mathrm{nm})$, the oscillator strength (f) and the excitation energy $\left(E_{\mathrm{ex}}\right)(\mathrm{eV})$ for the different studied oligomers. These values are calculated by ZINDO, TD/DFT and CIS methods starting with optimized geometry obtained at B3LYP/3-21G* level. $\lambda_{\max }$ increases asymptotically as the number of aromatic nuclei increases. The oscillator strength values $(f)$ show that the transition probability [47], increases with the chain length. Comparing with the wavelengths $\lambda_{\max }$ of the Poly(THP) $\left(\lambda_{\max }=318.58 \mathrm{~nm}\right)$ and Poly(EDOT) $\left(\lambda_{\max }=322.62 \mathrm{~nm}\right)$ [48], we can note that the superiority of the proposed copolymer is in the long chain [Cbz-(Edot) ${ }_{6}$-Cbz] $\left(\lambda_{\max }=\right.$ $561.72 \mathrm{~nm}$ ), and also the influence of the introduction of charge carriers (Table 6). Therefore, the theoretical calculations give a good description of optoelectronic properties of studied oligomers and can be employed to predict the electro-luminescence characteristics of other materials.

Table 6. Calculated absorption $\lambda_{\max }(\mathrm{nm})$, excitation energy $E_{\text {ex }}(\mathrm{eV})$ and oscillation strength $(f)$ for all oligomers [Cbz-(Edot) $)_{\mathrm{n}}$-Cbz] $(n=1-6)$.

\begin{tabular}{lccccccc}
\hline Method & & $n=1$ & $n=2$ & $n=3$ & $n=4$ & $n=5$ & $n=6$ \\
\hline Zindo & $\lambda_{\max }$ & $\mathbf{4 1 7 . 8 8}$ & $\mathbf{4 8 7 . 0 3}$ & $\mathbf{5 3 6 . 1 9}$ & $\mathbf{5 7 5 . 2 2}$ & $\mathbf{6 0 8 . 0 8}$ & $\mathbf{6 3 2 . 0 0}$ \\
& $E_{\mathrm{ex}}$ & 2.97 & 2.54 & 2.31 & 2.15 & 2.04 & 1.96 \\
& $f$ & 1.22 & 1.32 & 1.57 & 1.87 & 2.13 & 2.37 \\
TD/B3LYP/3-21G* & $\lambda_{\max }$ & $\mathbf{3 7 6 . 4 1}$ & $\mathbf{4 3 0 . 0 5}$ & $\mathbf{4 6 8 . 1 2}$ & $\mathbf{5 0 3 . 0 2}$ & $\mathbf{5 3 9 . 0 9}$ & $\mathbf{5 6 1 . 7 2}$ \\
& $E_{\mathrm{ex}}$ & 3.29 & 2.88 & 2.65 & 2.46 & 2.30 & 2.21 \\
& $f$ & 1.48 & 1.62 & 1.91 & 2.39 & 2.73 & 3.10 \\
CIS/3-21G* & $\lambda_{\max }$ & $\mathbf{2 9 1 . 3 5}$ & $\mathbf{3 2 7 . 0 0}$ & $\mathbf{3 4 9 . 8 8}$ & $\mathbf{3 6 8 . 9 5}$ & $\mathbf{3 8 6 . 4 7}$ & $\mathbf{3 9 8 . 2 1}$ \\
& $E_{\mathrm{ex}}$ & 4.25 & 3.79 & 3.54 & 3.36 & 3.21 & 3.11 \\
& $f$ & 1.65 & 1.96 & 2.38 & 2.93 & 3.34 & 3.69 \\
\hline
\end{tabular}

We list the excitation energies, oscillator strengths and configurations obtained by TD/DFT-B3LYP/3-21G* calculations for each oligomer [Cbz-(Edot) $)_{n}$-Cbz] $(n=1-6)$ in Table 7. All electronic transitions are of the $\pi \pi^{*}$ type and involve both subunits of the molecule. The largest oscillator strengths $(f)$ originate from $S_{0} \longrightarrow S_{1}$ electronic transition. Excitation to the $S_{1}$ state corresponds exclusively to the promotion of an electron from the HOMO to the LUMO. As in the case of the oscillator strengths, the absorption wavelengths arising from $S_{0} \rightarrow S_{1}$ electronic transition increase progressively with the increase of the conjugation lengths. It is reasonable, since HOMO $\rightarrow$ LUMO transition is predominant in $\mathrm{S}_{0} \rightarrow \mathrm{S}_{1}$ electronic transition and as seen in the analysis above that with the extending molecular size, the HOMO-LUMO gaps decrease. 
Table 7. Electronic transition data obtained by the TD/DFT-B3LYP/3-21G* calculation for all oligomers [Cbz-(Edot) $)_{\mathrm{n}}$-Cbz] $(\mathrm{n}=1-6)$.

\begin{tabular}{|c|c|c|c|c|c|}
\hline $\begin{array}{l}\text { Electronic } \\
\text { transitions }\end{array}$ & $\lambda_{\text {abs }}(\mathrm{nm})$ & $\begin{array}{l}E_{e x} \\
(e V)\end{array}$ & $\mathrm{f}$ & MO/character & Coeff \\
\hline \multicolumn{6}{|c|}{ [Cbz-(Edot) $)_{1-C b z]}$} \\
\hline $\mathrm{S}_{0} \longrightarrow \mathrm{S}_{1}$ & 376.41 & 3.29 & 1.48 & HOMO $\longrightarrow$ LUMO & 0.65 \\
\hline $\mathrm{S}_{0} \longrightarrow \mathrm{S}_{2}$ & 348.15 & 3.56 & 0.03 & $\mathrm{HOMO} \longrightarrow \mathrm{LUMO}+1$ & 0.66 \\
\hline $\mathrm{S}_{0} \longrightarrow \mathrm{S}_{3}$ & 346.78 & 3.58 & 0.04 & $\mathrm{HOMO} \longrightarrow \mathrm{LUMO}+2$ & 0.66 \\
\hline \multicolumn{6}{|c|}{ [Cbz-(Edot) $)_{2}$-Cbz] } \\
\hline $\mathrm{S}_{0} \longrightarrow \mathrm{S}_{1}$ & 430.05 & 2.88 & 1.62 & $\longrightarrow$ LUMO & 0.65 \\
\hline $\mathrm{S}_{0} \longrightarrow \mathrm{S}_{2}$ & 367.02 & 3.38 & 0.02 & HOMO-1 $\longrightarrow$ LUMO & 0.64 \\
\hline $\mathrm{S}_{0} \longrightarrow \mathrm{S}_{3}$ & 352.36 & 3.52 & 0.0009 & $\longrightarrow \mathrm{LUMO}+2$ & 0.46 \\
\hline \multicolumn{6}{|c|}{ [Cbz-(Edot) $)_{3}$-Cbz] } \\
\hline $\mathrm{S}_{0} \longrightarrow \mathrm{S}_{1}$ & 468.12 & 2.65 & 1.91 & $\longrightarrow$ LUMO & 0.65 \\
\hline $\mathrm{S}_{0} \longrightarrow \mathrm{S}_{2}$ & 399.15 & 3.11 & 0.03 & HOMO-1 $\longrightarrow$ LUMO & 0.62 \\
\hline $\mathrm{S}_{0} \longrightarrow \mathrm{S}_{3}$ & 375.33 & 3.30 & 0.08 & HOMO-2 $\longrightarrow$ LUMO & 0.66 \\
\hline \multicolumn{6}{|c|}{ [Cbz-(Edot) $)_{4}$-Cbz] } \\
\hline $\mathrm{S}_{0} \longrightarrow \mathrm{S}_{1}$ & 503.02 & 2.46 & 2.39 & $\longrightarrow$ LUMO & 0.65 \\
\hline $\mathrm{S}_{0} \longrightarrow \mathrm{S}_{2}$ & 431.07 & 2.88 & 0.0009 & HOMO-1 $\longrightarrow$ LUMO & 0.60 \\
\hline $\mathrm{S}_{0} \longrightarrow \mathrm{S}_{3}$ & 389.88 & 3.18 & 0.06 & HOMO-2 & 0.66 \\
\hline \multicolumn{6}{|c|}{ [Cbz-(Edot) $\left.)_{5}-\mathrm{Cbz}\right]$} \\
\hline $\mathrm{S}_{0} \longrightarrow \mathrm{S}_{1}$ & 539.09 & 2.30 & 2.73 & $\longrightarrow$ LUMO & 0.65 \\
\hline $\mathrm{S}_{0} \longrightarrow \mathrm{S}_{2}$ & 458.06 & 2.71 & 0.05 & HOMO-1 $\longrightarrow$ LUMO & 0.57 \\
\hline $\mathrm{S}_{0} \longrightarrow \mathrm{S}_{3}$ & 421.03 & 2.94 & 0.02 & $\longrightarrow$ LUMO+1 & 0.52 \\
\hline \multicolumn{6}{|c|}{ [Cbz-(Edot) $\left.{ }_{6}-\mathrm{Cbz}\right]$} \\
\hline $\mathrm{S}_{0} \longrightarrow \mathrm{S}_{1}$ & 561.72 & 2.21 & 3.10 & HOMO $\longrightarrow$ LUMO & 0.65 \\
\hline $\mathrm{S}_{0} \longrightarrow \mathrm{S}_{2}$ & 475.00 & 2.61 & 0.004 & HOMO-1 $\longrightarrow$ LUMO & 0.54 \\
\hline $\mathrm{S}_{0} \longrightarrow \mathrm{S}_{3}$ & 442.81 & 2.80 & 0.02 & $\longrightarrow$ LUMO+1 & 0.49 \\
\hline
\end{tabular}

\subsection{Bridging effect on optoelectronic properties}

In this part, we present a DFT (B3LYP/3-21G*) study of oligomers in which inter-ring torsional angles have been blocked by chemical bridging. This rigid bridge contains $\mathrm{C}=\mathrm{C}(\mathrm{CN})_{2}$ group. We will investigate the influence of bridging on (carbazolebithiophene-carbazole) [Cbz-(BThi)-Cbz] and (carbazole-quaterthiophene-carbazole) [Cbz-(QThi)-Cbz]. We focus on the electronical properties of these compounds and we will try to understand the effect of the bridging on the optical properties of these oligomers. We present in Fig. 4 the theoretical geometric structure of studied compounds. 


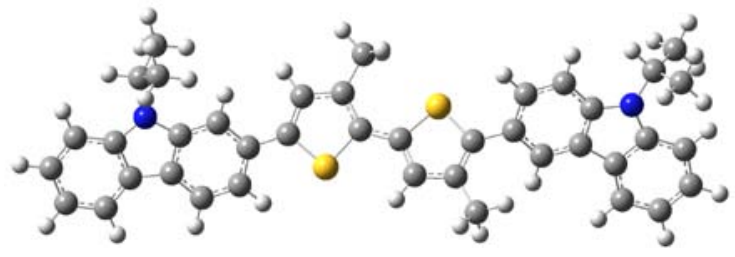

Cbz-(Mth) ${ }_{2}-\mathrm{Cbz}$

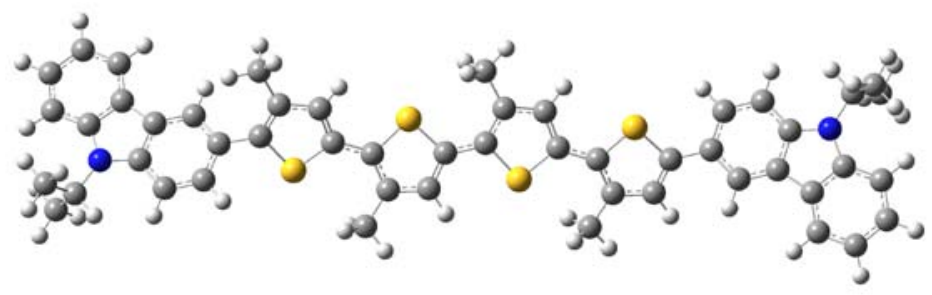

Cbz-(Mth) $)_{4}-\mathrm{Cbz}$

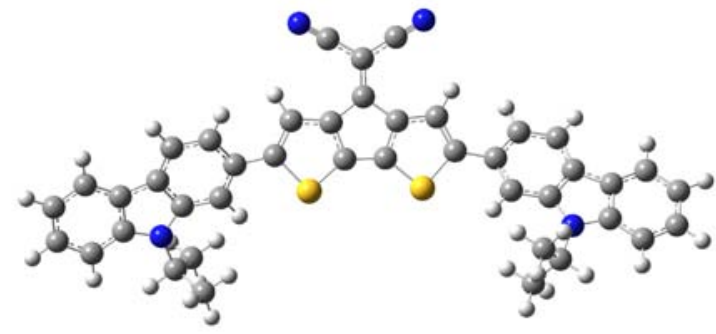

Cbz-(BThi C=C(CN $\left.)_{2}\right)-\mathrm{Cbz}$

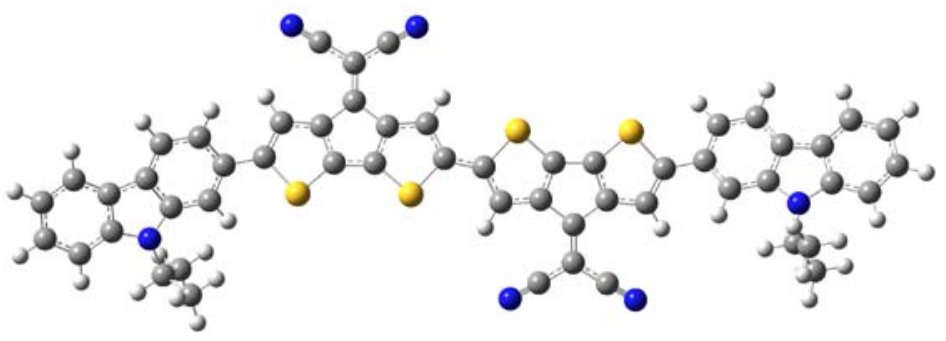

Cbz-(QThi C=C(CN) $)_{2}-\mathrm{Cbz}$

Fig. 4. The theoretical geometric structure of studied compounds.

In order to study the influence of bridging effects on the electronic properties, calculations were performed using B3LYP/3-21G* method. Table. 8 shows calculated values of HOMO, LUMO, and energy gaps $\left(\mathrm{E}_{\mathrm{g}}\right)$ for bridged [Cbz- $\left(\mathrm{BThiC}=\mathrm{C}(\mathrm{CN})_{2}\right)-\mathrm{Cbz}$ ], [Cbz-(QThiC $\left.\left.=\mathrm{C}(\mathrm{CN})_{2}\right)-\mathrm{Cbz}\right]$ and unbridged [Cbz-(Mth $\left.)_{\mathrm{n}}-\mathrm{Cbz}\right]$ and [Cbz-(Edot $)_{\mathrm{n}}-\mathrm{Cbz}$ for 
( $n=2$ and 4). Comparing the values obtained, we find that the bridging by the substituted $\mathrm{sp}^{2}$ carbon atom reduces the gaps energy, similar results were obtained in the case of substituted oligobithiophene [24].

The orbital patterns of the highest occupied molecular orbital HOMO and the lowest unoccupied molecular orbital LUMO calculation, for bridged [Cbz-(BThiC $\left.=\mathrm{C}(\mathrm{CN})_{2}\right)$ Cbz], unbridged [Cbz-(Mth) $)_{2}$-Cbz] and unbridged [Cbz-(Edot $)_{2}$-Cbz], are shown in Fig. 5. It is interesting to note that the contribution of the electron accepting group $\mathrm{C}=\mathrm{C}(\mathrm{CN})_{2}$ to the HOMO is negligibly small while it makes a significant contribution to the LUMO. In the light of these results, one can rationalize the small band gap values obtained in this compound.

Table 8. Calculated HOMO, LUMO, and gap energies (eV) of the compounds, unbridged [Cbz(Mth) $)_{\mathrm{n}}-\mathrm{Cbz}$ ], unbridged [Cbz-(Edot) $\left.)_{\mathrm{n}}-\mathrm{Cbz}\right]$ for $\mathrm{n}=2$ and 4, and bridged [Cbz-(BThiC $\left.=\mathrm{C}(\mathrm{CN})_{2}\right)$ $\mathrm{Cbz}]$ and [Cbz-(QThiC= $\left.\left.\mathrm{C}(\mathrm{CN})_{2}\right)-\mathrm{Cbz}\right]$.

\begin{tabular}{|c|c|c|c|}
\hline Polymers & $E_{\text {НОМО }}$ & $E_{\text {LUMO }}$ & $E_{\mathrm{g}}$ \\
\hline [Cbz-(Mth) $)_{2}$-Cbz] (unbridged) & -4.825 & -1.373 & 3.452 \\
\hline [Cbz-(Edot) ${ }_{2}$-Cbz] (unbridged) & -4.477 & -1.301 & 3.176 \\
\hline [Cbz-(BThiC=C(CN) $\left.\left.)_{2}\right)-\mathrm{Cbz}\right]$ & -5.266 & -3.263 & 2.003 \\
\hline [Cbz-(Mth) ${ }_{4}$-Cbz] (unbridged) & -4.539 & -1.671 & 2.868 \\
\hline [Cbz-(Edot) ${ }_{4}-\mathrm{Cbz}$ ] (unbridged) & -4.287 & -1.526 & 2.761 \\
\hline [Cbz-(QThiC=C(CN) $\left.\left.)_{2}\right)-\mathrm{Cbz}\right]$ & -5.245 & -3.496 & 1.749 \\
\hline
\end{tabular}

LUMO
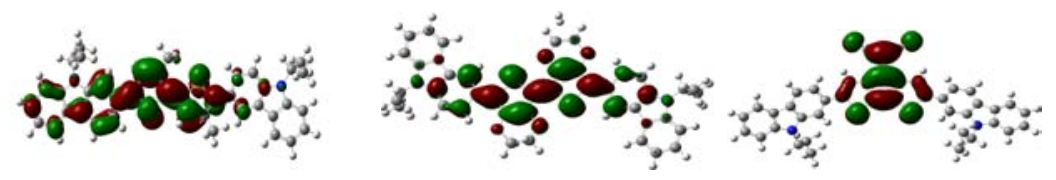

HOMO

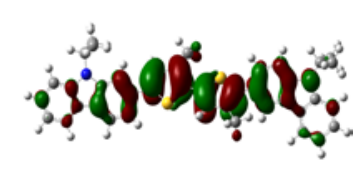

Cbz-(Mth) $)_{2}-\mathrm{Cbz}$

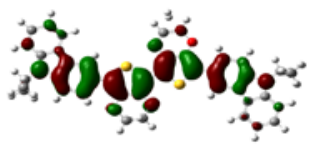

Cbz-(Edot) $)_{2}-\mathrm{Cbz}$

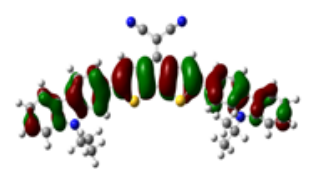

Cbz-(BThi C=C(CN) $)_{2}-\mathrm{Cbz}$

Fig. 5. HOMO and LUMO molecular orbital of the studied bridged [Cbz-(BThiC $\left.=\mathrm{C}(\mathrm{CN})_{2}\right)-\mathrm{Cbz}$, unbridged [Cbz-(Edot) ${ }_{2}$-Cbz] and unbridged[Cbz-(Mth) $\left.)_{2}-\mathrm{Cbz}\right]$.

To investigate the insertion effect of $\mathrm{C}=\mathrm{C}(\mathrm{CN})_{2}$ group on electronic properties of the [Cbz-(Thi) $)_{n}-\mathrm{Cbz}$ ( $\mathrm{n}=2$ and 4), we presented in Table. 9 the calculated absorption $\lambda_{\max }$ values of the oligomers : bridged [Cbz-(BThiC $\left.=\mathrm{C}(\mathrm{CN})_{2}\right)-\mathrm{Cbz}$, [Cbz-(QThiC $\left.=\mathrm{C}(\mathrm{CN})_{2}\right)-$ $\mathrm{Cbz}$ ], unbridged [Cbz-(Edot) $)_{\mathrm{n}}-\mathrm{Cbz}$ ] and unbridged [Cbz-(Mth) $)_{\mathrm{n}}-\mathrm{Cbz}$ ( $\mathrm{n}=2$ and 4). The 
values are calculated by TD/DFT method starting with optimized geometry obtained at B3LYP/3-21G*. Comparing the wavelengths $\lambda_{\max }$ of the oligomers, we note that the bridged [Cbz-(BThiC $\left.\left.=\mathrm{C}(\mathrm{CN})_{2}\right)-\mathrm{Cbz}\right]$ and [Cbz-(QThiC $\left.=\mathrm{C}(\mathrm{CN})_{2}\right)-\mathrm{Cbz}$ ] exhibits the longest wavelengths values. Introducing the $\mathrm{C}=\mathrm{C}(\mathrm{CN})_{2}$ group into oligomers backone affects the electronic structure by donating charge carriers thereby lowering the energy band gap and raising the conjugation length.

Table 9. Calculated absorption $\lambda_{\max }(\mathrm{nm})$, excitation energy (eV) and oscillation strength (f) for bridged [Cbz-(BThiC $\left.=\mathrm{C}(\mathrm{CN})_{2}\right)-\mathrm{Cbz}$ ], [Cbz-(QThiC $\left.=\mathrm{C}(\mathrm{CN})_{2}\right)-\mathrm{Cbz}$ ], unbridged [Cbz-(Edot $)_{\mathrm{n}}-\mathrm{Cbz}$ ] and unbridged [Cbz-(Mth) $)_{n}-\mathrm{Cbz}$ ] ( $\mathrm{n}=2$ and 4) by TD/DFT level.

\begin{tabular}{lccc}
\hline Polymers & $\lambda_{\max }$ & $f$ & $\begin{array}{c}\text { Excitation } \\
\text { energy }\end{array}$ \\
\hline [Cbz-(Mth) -Cbz] (unbridged) $^{-}$ & 397.80 & 1.64 & 3.12 \\
[Cbz-(Edot) ${ }_{2}$-Cbz] (unbridged) & 430.05 & 1.62 & 2.88 \\
[Cbz-(BThiC=C(CN) $)_{2}$-Cbz] & $\mathbf{8 8 4 . 2 7}$ & $\mathbf{0 . 0 8}$ & $\mathbf{1 . 4 0}$ \\
[Cbz-(Mth) ${ }_{4}$-Cbz] (unbridged) & 478.75 & 2.35 & 2.59 \\
[Cbz-(Edot) $)_{4}$-Cbz] (unbridged) & 503.02 & 2.39 & 2.46 \\
[Cbz-(QThiC=C(CN) $)_{2}$-Cbz] & $\mathbf{9 9 1 . 2 1}$ & $\mathbf{0 . 2 2}$ & $\mathbf{1 . 2 5}$ \\
\hline
\end{tabular}

\section{Conclusion}

The structural and electronic properties of 3, 4-ethylenedioxythiophene (EDOT) based carbazole (Cbz) were studied for ground state from the [Cbz-(Edot $\left.)_{n}-c b z\right](n=1-4)$, by B3LYP/3-21G* level. The behavior of torsional angles has been discussed in detail. The stable conformation of all oligomers is the anti-planar conformation. Our calculated results indicate that all the carbazole-based EDOT oligomers improve the hole injection due to the higher HOMO levels and the lower LUMO energies, which contribute to the highly improved electron-accepting and transporting properties. The gap energy calculated from all oligomers, decreases with the chain length, and the values of optical absorption $\lambda_{\max }$ calculated by the three methods (ZINDO, TD/DFT et CIS), increase with the number of monomers. The first electronic transition gives rise to the largest values of the oscillator strength in each oligomer. The absorption spectra of all polymers indicates a strong $\pi$-electron delocalization along the oligomeric chain. These points are essential for light-emetting polymers, and provide the opportunity of tuning the electronic and optical properties of the oligomers. The insertion of a $\mathrm{C}=\mathrm{C}(\mathrm{CN})_{2}$ group into oligomers backone affects the electronic structure, leading to a reduction of the energy gaps and to a raising of the conjugation length.

Finally, the theoretical results showed that, by modification of chemical structures could greatly modulate and improve the electronic and optical properties of pristine polymers. Furthermore, using theoretical methodologies, we showed that is possible to 
predict reasonably the electronic properties of conjugated systems and we are convinced that the systematic use of those theoretical tools should contribute to orientate the synthesis efforts and help in understanding the structure-properties relation of these conjugated materials.

\section{References}

1. G. Heywang, F. Jonas, Adv. Mater. 4, 116 (1992). http://dx.doi.org/10.1002/adma.19920040213

2. A. Dodabalapur, L. Torsi, and H. E. Katz, Science 268, 270 (1995). http://dx.doi.org/10.1126/science.268.5208.270

3. H. H. Kuhn, A. D. Child, and W. C. Kimbrell, Synth. Met. 71, 2139 (1995). http://dx.doi.org/10.1016/0379-6779(94)03198-F

4. J.-F. Morin and M. Leclerc, Macromolecules 34, 4680 (2001). http://dx.doi.org/10.1021/ma010152u

5. G. Zotti, G. Schiavon, S. Zecchin, J.-F. Morin, and M. Leclerc, Macromolecules 35, 2122 (2002). http://dx.doi.org/10.1021/ma011311c

6. J.-F. Morin and M. Leclerc, Macromolecules 35, 8413 (2002). http://dx.doi.org/10.1021/ma020880x

7. J.-F. Morin, S. Beaupre, M. Leclerc, I. Levesque, and M. D’Iorio, Appl. Phys. Lett. 80, 341 (2002). http://dx.doi.org/10.1063/1.1433917

8. F. Garnier, G. Horowitz, X. Peng, and D. Fichou, Adv. Mater. 2, 562 (1990).

9. R. E. Gill, G. G. Malliaras, J. Wildeman, G. Hadziioannou, Adv. Mater. 6, 132 (1994). http://dx.doi.org/10.1002/adma.19940060206

10. M. Belletete, M. Bedard, M. Leclerc, G. Durocher, Synthetic Met. 146, 99 (2004). http://dx.doi.org/10.1016/j.synthmet.2004.06.012

11. M. Belletete, M. Bedard, M. Leclerc, G. Durocher, J. Mol. Struct. (TheoChem) 679, 9 (2004). http://dx.doi.org/10.1016/j.theochem.2004.02.045

12. L. Yang, J. Feng, A. Ren, Polymer. 46, 10970 (2005). http://dx.doi.org/10.1016/j.polymer.2005.09.050

13. L. Yang, J. K. Feng, A. M. Ren, J. Z. Sun, Polymer. 47, 1397 (2006). http://dx.doi.org/10.1016/j.polymer.2005.12.065

14. S. Surmtir, S. Hannongbua, P. Wolschann, J. Mol. Struct. (TheoChem) 807, 109 (2007). http://dx.doi.org/10.1016/j.theochem.2006.12.025

15. L. B. Goenendaal, F. Jonas, D. Freitag, H. Pielartzik, J. R. Reynolds, Adv. Mater. 12, 481 (2000). http://dx.doi.org/10.1002/(SICI)1521-4095(200004)12:7<481::AID-ADMA481>3.0.CO;2-C

16. J. Apperloo, L. B. Groenendaal, H. Verheyen, M. Jayakannan, R. A. Janssen, A. Dkhissi, D. Beljonne, R. Lazzaroni, J. L. Brédas, Chem. Eur. J. 8, 2384 (2002). http://dx.doi.org/10.1002/1521-3765(20020517)8:10<2384::AID-CHEM2384>3.0.CO;2-L

17. A. P. Kulkarni, Y. Zhu, S. A. Jenekhe, Macromolecules 38, 553 (2005). http://dx.doi.org/10.1021/ma048118d

18. C. J. Dubois, K. A. Abboud, J. R. Reynolds, J. Phys Chem. B 108, 8550 (2004). http://dx.doi.org/10.1021/jp037013u

19. A. Berlin, A. Zanelli, Chem Mater. 16, 3667 (2004). http://dx.doi.org/10.1021/cm049572z

20. S. Akoudad, J. Roncali, Chem Commun. 9, 2081 (1998). http://dx.doi.org/10.1039/a804992k

21. A. Dkhissi, F. Louwet, L. Groenendaal, D. Beljonne, R. Lazzaroni, J. L. Brédas, Chem. Phys. Lett. 359, 466 (2002). http://dx.doi.org/10.1016/S0009-2614(02)00651-6

22. A. S. Sarac, E. Parlak, E. Sezer, Journal of Applied Polymer Science. 103, 795 (2007). http://dx.doi.org/10.1002/app.25114

23. J. Roncali, Chem. Rev. 97, 173 (1997). http://dx.doi.org/10.1021/cr950257t 
24. S. M. Bouzzine, A. Makayssi, M. Hamidi, M. Bouachrine, J. Molec. Struct.: Theochem. 851, 254 (2008). http://dx.doi.org/10.1016/j.theochem.2007.11.023

25. A. D. Becke, J. Chem. Phys. 98, 5648 (1993). http://dx.doi.org/10.1063/1.464913

26. M. J. Frisch, G. W. Trucks, H. B. Schlegel, G. E. Scuseria, M. A. Robb, J. R. Cheeseman, J. A. Montgomery, T. Vreven, Jr., K. N. Kudin, J. C. Burant, J. M. Millam, S. S. Iyengar, J. Tomasi, V. Barone, B. Mennucci, M. Cossi, G. Scalmani, N. Rega, G. A. Petersson, H. Nakatsuji, M. Hada, M. Ehara, K. Toyota, R. Fukuda, J. Hasegawa, M. Ishida, T. Nakajima, Y. Honda, O. Kitao, H. Nakai, M. Klene, X. Li, J. E. Knox, H. P. Hratchian, J. B. Cross, C. Adamo, J. Jaramillo, R. Gomperts, R. E. Stratmann, O. Yazyev, A. J. Austin, R. Cammi, C. Pomelli, J. W. Ochterski, P. Y. Ayala, K. Morokuma, G. A. Voth, P. Salvador, J. J. Dannenberg, V. G. Zakrzewski, S. Dapprich, A. D. Daniels, M. C. Strain, O. Farkas, D. K. Malick, A. D. Rabuck, K. Raghavachari, J. B. Foresman, J. V. Ortiz, Q. Cui, A. G. Baboul, S. Clifford, J. Cioslowski, B. B. Stefanov, G. Liu, A. Liashenko, P. Piskorz, I. Komaromi, R. L. Martin, D. J. Fox, T. Keith, M. A. Al- Laham, C. Y. Peng, A. Nanayakkara, M. Challacombe, P. M. W. Gill, B. Johnson, W. Chen, M. W. Wong, C. Gonzalez, J. A. Pople, GAUSSIAN 03, Revision B.04, Gaussian, Inc., Pittsburgh PA, (2003).

27. J. S. Binkley, J. A. Pople, and W. J. Hehre, J. Am. Chem. Sos. 102, 939 (1980). http://dx.doi.org/10.1021/ja00523a008

28. K. D. Dobbs and W. J. Hehre, J. Comp. Chem. 7, 359 (1986). http://dx.doi.org/10.1002/jcc.540070313

29. W. J. Pierto, M. M. Francl, W. J. Hehre, D. J. Defrees, J. A. Pople, J. S. Binkley, J. Am. Chem. Sos. 104, 5039 (1982). http://dx.doi.org/10.1021/ja00383a007

30. K. D. Dobbs and W. J. Hehre, J. Comp. Chem. 8, 880 (1987). http://dx.doi.org/10.1002/jcc.540080615

31. J. Ma, S-H. Li, Y-S. Jiang. Macromolecules. 35, 1109 (2002). http://dx.doi.org/10.1021/ma011279m

32. G-L. Zhang, J. Ma, Y-S. Jiang. Macromolecules. 36, 2130 (2003). http://dx.doi.org/10.1021/ma021694u

33. H. Cao, J. Ma, G-L. Zhang, Y-S. Jiang. Macromolecules. 38, 1123 (2005). http://dx.doi.org/10.1021/ma048534y

34. X. Zhou, A-M. Ren, J-K. Feng, Polymer. 57, 7747 (2004). http://dx.doi.org/10.1016/j.polymer.2004.08.070

35. J. B. Foresman, M. Head-Gordon, J. A. Pople, M. J. Frisch, J. Chem. Phys. 96, 135 (1992). http://dx.doi.org/10.1021/j100180a030

36. J. F. Stanton, J. Gauss, N. Ishikawa, M. Head-Gordon, J. Chem. Phys. 103, 4160 (1995). http://dx.doi.org/10.1063/1.469601

37. S. Y. Yang, Y. H. Kan, G. C. Yang, Z. M. Su, Lu. Zhao, Chem. Phys Lett. 429, 108 (2006).

38. C. Alemán, J. Casanovas, J. Phys. Chem. 108, 1440 (2004). http://dx.doi.org/10.1021/jp0369600

39. C. Alemán, E. Armelin, J. I. Iribarren, F. Liesa, M. Laso, J. Casanovas, Synth Met. 149, 151 (2005). http://dx.doi.org/10.1016/j.synthmet.2004.12.012

40. C. Alemán, L. Julià, J. Phys. Chem. 100, 14661 (1996). http://dx.doi.org/10.1021/jp9604103

41. E. Ortí, P. M. Viruela, J. Sanchéz-Marín, F. Tomás, J. Phys. Chem. 99, 4955 (1995). http://dx.doi.org/10.1021/j100014a014

42. A. Karpfen, C. H. Choi, M. Kertesz, J. Phys. Chem. A 101, 7426 (1997). http://dx.doi.org/10.1021/jp9716061

43. M. Breza, V. Lukeš, I. Vrábel, J. Mol. Struct. (Theochem). 572, 151 (2001). http://dx.doi.org/10.1016/S0166-1280(01)00623-6

44. L. Ferza, H. Zgou, M. Bouachrine, M. Hamidi, Phys. Chem. News. 26, 124 (2005).

45. P. J. Hay. J Phys Chem. A 106, 634 (2002). http://dx.doi.org/10.1021/jp013949w

46. A. Curioni, W. Andreoni, R. Treusch, F. J. Himpsel, E. Haskal, P. Seidler, C. Heske, S. Kakar, T. van Buuren, and L. J. Terminello, J. Appl. Phys. Lett. 72, 1575 (1998). http://dx.doi.org/10.1063/1.121119 
47. M. Hesse, H. Meier, B. Zeeh, Méthodes spectroscopiques pour la chimie organique, Edited by MASSON, Paris, pour la traduction française (1997).

48. D. M. Welsh, A. Kamar, M. C. Mornaut, J. R. Reynolds, Synth. Met. 102, 967 (1999).

http://dx.doi.org/10.1016/S0379-6779(98)01014-5 